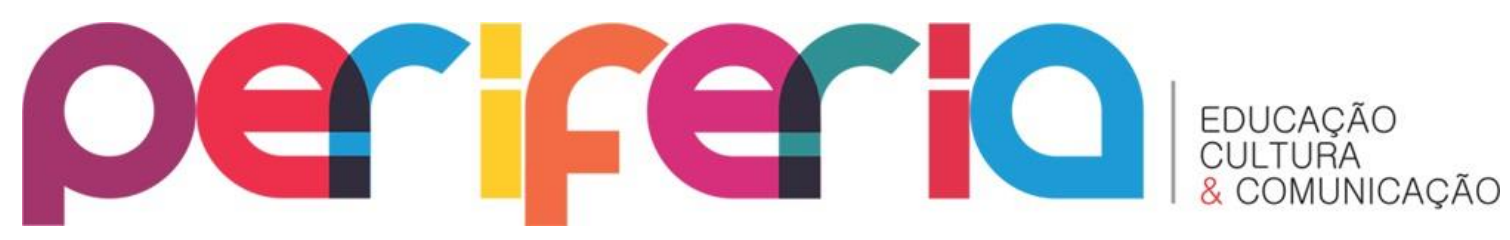

\title{
POLÍTICAS DE AÇÃO AFIRMATIVA E O DIREITO À EDUCAÇÃO: DESAFIOS DE ACESSO E DE PERMANÊNCIA DE ESTUDANTES INDÍGENAS NO ESTADO DO RIO DE JANEIRO ${ }^{1}$
}

\author{
Kelly Russo ${ }^{2}$ \\ Universidade do Estado do Rio de Janeiro \\ Edson Diniz ${ }^{3}$ \\ Universidade do Estado do Rio de Janeiro
}

\section{RESUMO}

No Brasil, o cenário das políticas públicas de educação superior tem sido marcado pela intensificação dos debates acerca do acesso diferenciado de grupos socialmente desfavorecidos à universidade, por meio de ações afirmativas. Em consequência, o direito à educação e um conjunto de questões muito variado, tem desafiado a universidade brasileira, principalmente quando o assunto é o acesso e a permanência de estudantes indígenas. Através da revisão bibliográfica, análise de documentação e entrevistas realizadas com estudantes indígenas universitários, constatamos que o direito ao acesso à universidade não significa o direito ao ensino superior.

Palavras-chave: Estudantes indígenas; Ação afirmativa; Ensino Superior.

\section{AFFIRMATIVE ACTION POLICIES AND THE RIGHT TO EDUCATION: CHALLENGES OF ACCESS AND PERMANENCE OF INDIGENOUS STUDENTS IN THE STATE OF RIO DE JANEIRO \\ ABSTRACT}

In Brazil, the setting of public policy for higher education has been marked by the intensification of debates about the differential access to the university of socially disadvantaged groups, through affirmative action. Consequently, the right to education and a set of very varied issues, has challenged the Brazilian university, especially when it comes to access and permanence of indigenous students. Through literature review, analysis of documentation and interviews with indigenous university students, found that the right of access to university does not mean the right to higher education.

Keywords: Indigenous students; Affirmative action; Higher Education.

\footnotetext{
${ }^{1}$ Texto apresentado no VIII Encontro Nacional da ANDHEP na Faculdade de Direito da USP no grupo de trabalho políticas públicas e Direitos Humanos no dia 30/04/2014.

2 Professora Adjunta do Departamento de Formação de Professores da Faculdade de Educação da Baixada Fluminense (FEBF-UERJ) e Professora do Programa de Pós-Graduação em Educação, Cultura e Comunicação em Periferias Urbanas da UERJ (PPGECC/FEBF/UERJ). E-mail: kellyrussobr@gmail.com

${ }^{3}$ Mestrando em Educação, Cultura e Comunicação pela Faculdade de Educação da Baixada Fluminense (UERJ) e membro do grupo de pesquisa sobre Movimentos Sociais, Educação em Direitos Humanos e a Afirmação das diferenças na Escola Pública Brasileira. E-mail: edsondiniz6@hotmail.com
} 


\section{periferio}

\section{POLÍTICAS DE AÇÃO AFIRMATIVA E O DIREITO À EDUCAÇÃO: DESAFIOS DE ACESSO E DE PERMANÊNCIA DE ESTUDANTES INDÍGENAS NO ESTADO DO RIO DE JANEIRO}

O domínio maior de novos conceitos e estratégias da sociedade nacional e mundial possibilitará maior capacidade de gerenciamento dos problemas que afetam as nossas organizações e comunidades, principalmente nas tomadas de decisão diante dos conflitos de interesse próprios do ambiente de contato interétnico, de modo que os direitos e interesses indígenas sejam respeitados e preservados. (BANIWA, 2008) ${ }^{4}$

Este artigo tem por objetivo discutir as iniciativas relacionadas à democratização do ensino superior. O recorte, ação afirmativa para estudantes indígenas universitários no estado do Rio de Janeiro, se delineou após verificarmos a escassez de estudos nesta direção. No Brasil, existem 305 diferentes etnias indígenas, que somam cerca de 800 mil pessoas. Desse total, quase um terço desta população está fora das aldeias ou territórios indígenas, habitando nas cidades, e uma porcentagem significativa dessa população está cursando o Ensino Superior. Segundo estimativas compiladas no Conselho Nacional de Educação e fornecidas pela Fundação Nacional do Índio (FUNAI), existem atualmente no Brasil cerca de 5.000 estudantes universitários indígenas, entre formados e formandos. Até o presente momento, não foram sistematizados dados oficiais sobre a real presença dessa população nas instituições de ensino superior brasileiras. Menos ainda se sabe sobre suas trajetórias rumo à universidade e a possível influência, ainda que recente, de políticas de ação afirmativa no cotidiano dessas universidades.

Discutir o acesso de grupos historicamente excluídos da universidade também inclui um debate aprofundado sobre a permanência desses estudantes. Em relação aos

\footnotetext{
4 Edílson Martins Baniwa, durante palestra realizada em 14/01/2008, no seminário: “Acesso $e$ Permanência dos Estudantes Indígenas nas Universidades: Comemoração ou Reflexão?", organizado pelo projeto Trilhas do Conhecimento. Texto acessado em 14/04/2014. Disponível em: (http://www.trilhasdeconhecimentos.etc.br/relatorio_mariana_02.htm).
} 


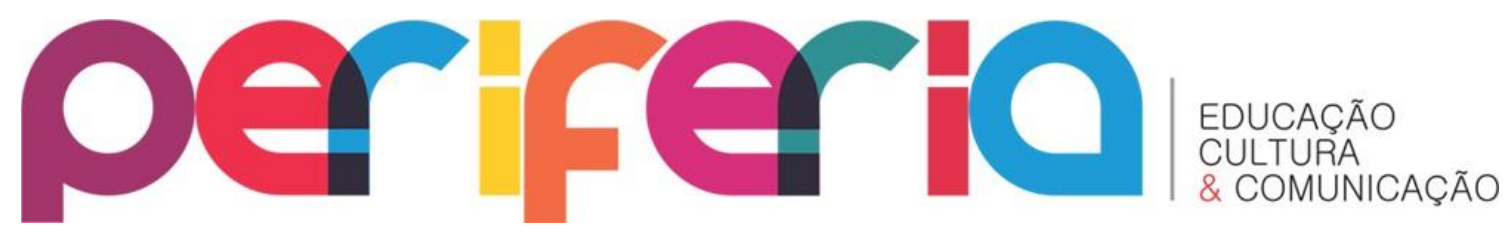

povos indígenas, essa permanência não se garante apenas com bolsas de financiamento, ou a implantação de programas, tais como: primeiro Emprego Acadêmico ${ }^{5}$, bolsas de trabalho, ampliação de cursos noturnos, seguindo, assim, a lógica dos pacotes prontos. No tocante à situação de imensa diversidade existente entre os povos indígenas brasileiros, é necessário abrir diálogo com os próprios estudantes indígenas e suas comunidades para definir democraticamente políticas de permanência adequadas às suas necessidades concretas, afinal, se os estudantes indígenas chegam às universidades, tem sido bastante representativo os índices de evasão desse grupo (CAJUEIRO, 2008).

Sendo assim, é também primordial que as diferenças culturais dos povos indígenas sejam reconhecidas, pois manifestam sociedades diferenciadas, com traços culturais, línguas, religiões próprias e etnias específicas. Esta diversidade deveria compor a premissa de uma educação efetivamente inclusiva capaz de dialogar com essas especificidades. Há, portanto, que se identificar e propor algumas repostas eficazes, no sentido de efetivar o ensino que os povos indígenas reivindicam há décadas: uma educação diferenciada e de qualidade.

Em relação ao ensino superior, objeto deste artigo, os desafios ainda são muitos, principalmente quando o enfoque é o acesso de estudantes indígenas em universidades do Estado do Rio de Janeiro. Ao analisar a produção bibliográfica, identificamos uma lacuna no que diz respeito às ações afirmativas para ingresso e permanência de estudantes universitários indígenas no Estado do Rio de Janeiro. Além disso, ainda mais escassos são os estudos realizados sobre a questão indígena em contextos urbanos.

Este artigo está organizado em quatro partes. Na primeira, discutimos o direito à educação, dando ênfase ao direito ao ensino superior. Na segunda, apresentamos uma breve reflexão sobre as ações afirmativas na área educacional e as políticas de cotas para indígenas. Na terceira parte do texto, analisamos as entrevistas realizadas

\footnotetext{
${ }^{5}$ TORRES, Ceres Maria Ramires et al. A contra-reforma da educação superior: uma análise do ANDES-SN das principais iniciativas do Governo de Lula da Silva. Brasília, publicação do Grupo de Trabalho de Política Educacional, 2004. (http://www.andes.org.br acessado em dezembro de 2013).
} 


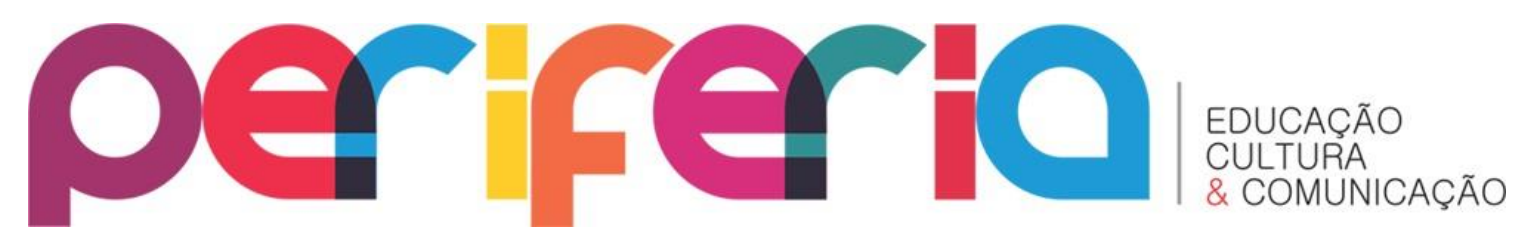

com estudantes universitários indígenas no estado do Rio de Janeiro e, por último, procuramos apontar algumas reflexões finais sobre o assunto.

\section{POVOS INDÍGENAS E O DIREITO AO ENSINO SUPERIOR}

Para Souza Lima e Hoffmann (2004, p.7), é preciso perceber "dois vieses diferentes, mas historicamente entrelaçados, que têm sido percebidos de modo separado e que, todavia, confluem na busca dos povos indígenas por formação no ensino superior." Os dois vieses a que os autores se referem são: a busca por cursos de formação específica para professores indígenas e a procura por capacitação para gerenciar seus territórios. Ambas as questões tocam na situação de povos tutelados, que ainda hoje essas populações precisam se confrontar.

Só com a Constituição de 1988 teve fim, pelo menos oficialmente, o regime tutelar. Deixa de ser atribuição do Estado legislar sobre a integração dos povos indígenas, ou seja, sua desintegração como povos etnicamente diferenciados. Pela primeira vez no Estado brasileiro os povos originários tiveram garantidos seus direitos à terra e à educação diferenciada, tendo afirmado, pelo menos no texto da lei, seu direito à diferença. Desta forma, outro tipo de educação escolar indígena passou a ser exigida, e estava regida, em linhas gerais, por quatro eixos básicos: bilíngue, específica, diferenciada e intercultural. A partir daí se fortalece a demanda indígena por formação de professores em cursos específicos de licenciatura (Licenciaturas Interculturais) para atuarem nas escolas indígenas, iniciando, assim, uma forte demanda pela ampliação da formação escolar voltada para essas populações.

Mas não só ela: tornou-se presente na pauta do movimento indígena a necessidade de formação de seus próprios quadros para atuação nos seus próprios territórios, sem interlocutores não índios, a partir da mesma perspectiva não tutelar e emancipatória do pós-constituinte. Dá-se início ao debate sobre a importância da educação superior para os povos indígenas, visando que fosse além da formação de professores nas Licenciaturas Interculturais.

Mas, como apontam Souza Lima e Hoffmann: 


\section{periferio}

Ao incluir os indígenas nas universidades há que se repensar as carreiras universitárias, as disciplinas, abrir novas (e inovadoras) áreas de pesquisa, selecionar e repensar os conteúdos curriculares que têm sido ministrados e testar o quanto estruturas, que acabaram se tornando tão burocratizadas e centralizadoras, podem suportar se colocar ao serviço de coletividades vivas histórica e culturalmente diferenciadas. (LIMA e HOFFMANN, 2004, p.17)

Por outro lado, as universidades também devem estar prontas para se indagarem sobre o quanto podem beneficiar-se com a presença indígena, vivificandose e ampliando-se, na construção de um mundo de tolerância e riqueza simbólica em que não bastará mais a repetição ampliada de paradigmas do horizonte capitalista contemporâneo. Desse modo, as políticas de ação afirmativa e de inserção de estudantes indígenas nas universidades precisam ter características diferenciadas e específicas para que, de fato, esses alunos sejam incluídos no Ensino Superior, como discutiremos melhor a seguir.

\section{AÇÃO AFIRMATIVA, ACESSO E PERMANÊNCIA DE INDÍGENAS NA UNIVERSIDADE: TENSÕES E DESAFIOS}

De acordo com Souza Lima e Hoffmann:

As políticas de ação afirmativa precisam adequar-se mais amplamente às especificidades da situação indígena, criando mecanismos de acesso à universidade que não reproduzam simplesmente as alternativas pensadas para o contexto das populações afrodescendentes, levando em consideração a necessidade de instituir políticas voltadas para povos, isto é, capazes de beneficiar, mais do que indivíduos (ainda que por meio deles), coletividades que pretendem manter-se culturalmente diferenciadas. (LIMA e HOFFMANN, 2004, p. 13)

Para que possamos discutir o sistema de cotas para o ingresso nas Universidades, especificamente dos indígenas, é necessário, antes, contextualizar o sistema de Ensino Fundamental e Médio pelo qual eles têm acesso ao ensino superior. Qual é a possibilidade de os indígenas usufruírem das cotas, se a maioria não conclui o 


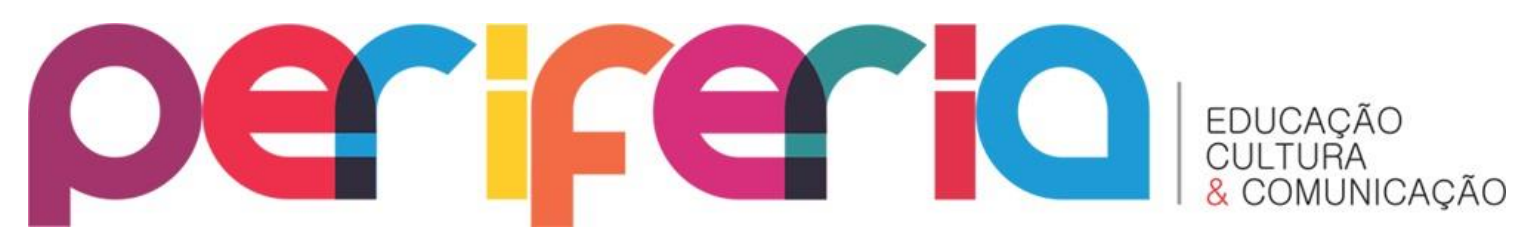

Ensino Fundamental? Qual a realidade escolar que eles enfrentam? Cotas para quem tem acesso à Universidade, mas sem acesso à conclusão do nível escolar básico? Estas questões são um grande desafio para a sociedade, para as entidades governamentais e instituições de ensino que atuam para a efetivação de políticas públicas nos segmentos das minorias excluídas.

Neste sentindo, as cotas de acesso às universidades irão garantir cursos adequados que respeitem o convívio com os indígenas, ou será mais um processo de exclusão e preconceito com a cultura deles? $\mathrm{O}$ acesso à universidade brasileira sempre foi piramidal, ou seja, do Ensino Fundamental até a universidade existe um filtro, e é a minoria que consegue chegar aos bancos da educação superior.

O ingresso e a permanência dos indígenas no espaço universitário e urbano tornam-se desafiadores para esses sujeitos que passam a aprender, a vivenciar e a intercambiar diferentes perspectivas, concepções e experiências, provocando e sendo por elas provocados a refletirem sobre sua identidade étnica. Além disso, como alertam os mesmos autores, as cotas, no caso dos indígenas, não são suficientes sem mudanças nas estruturas universitárias, de modo a que estas reflitam sobre suas práticas a partir da diferença étnica.

A política pública de educação tem um papel fundamental para diminuir a distância e o preconceito entre indígenas e não indígenas, para a garantia dos direitos sociais. São necessárias mudanças amplas, consistentes e que integrem diversas ações entre as políticas públicas. Há que se identificar e propor algumas repostas eficazes, no sentido de efetivar a escola que os povos indígenas reivindicam há décadas: uma educação diferenciada e de qualidade.

Nenhuma política pública terá sucesso se não estiver numa perspectiva de intersetorialidade com as demais políticas. Para que as cotas aos povos indígenas sejam de fato uma conquista, e não um caráter ilusionista, é necessário que haja a participação das políticas de assistência, de saúde, de habitação, de trabalho, entre outras. Na verdade, as cotas étnicas de acesso às universidades estão sendo pensadas isoladamente, desconsiderando que os povos indígenas possuem suas particularidades 


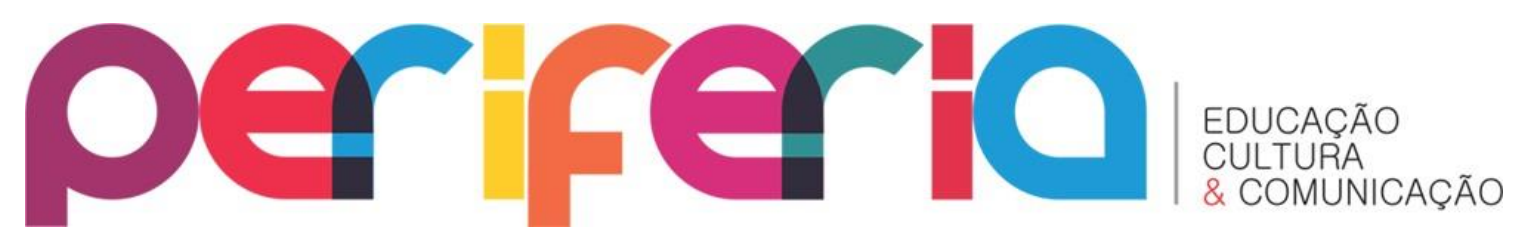

regionais, diferenças culturais, formas coletivas de organização, e que o padrão das cotas existentes não leva em conta estas diversidades.

As cotas ainda representam uma reforma compensatória e uma alternativa paliativa de inclusão social. Porém, sabemos que, sem estas, alguns indígenas jamais teriam acesso às universidades, e, quando as tem, encontram o obstáculo da permanência. Diante disso, uma reflexão mais cuidadosa, e não acabada, permanece nos inquietando: pensar em cotas é pensar "para quem e a serviço de quem?" Tratase, acima de tudo, de reconhecer a pluralidade dos povos indígenas e o que agregam à pluralidade da vida social no Brasil.

\section{CONHECENDO OS SUJEITOS DA POLÍTICA DE AÇÕES AFIRMATIVAS: ENTREVISTAS COM UNIVERSITÁRIOS INDÍGENAS}

Durante os meses de agosto a novembro de 2013, foram realizadas cinco entrevistas com universitários indígenas moradores do estado do Rio de Janeiro. A justificativa para o número reduzido de estudantes foi a ausência de estudos prévios sobre o tema e a inexistência de qualquer levantamento sobre estudantes indígenas no estado. Sendo assim, devido à grande dificuldade em encontrar informações sobre estudantes indígenas matriculados em universidades, optamos por utilizar a técnica conhecida como snowball ou "bola de neve" (VALENTIM, 2012). Nessa técnica, cada integrante indica um outro conhecido que esteja dentro do perfil de interesse da pesquisa. Em nosso caso, cada universitário indígena passou o contato de outro a ser entrevistado. Apesar de reconhecer que esse é um número pequeno de entrevistas, e que daremos continuidade a essa pesquisa, acreditamos ser de grande importância discutirmos essa temática, visto a escassez de pesquisas que se debrucem sobre a questão no país e principalmente, no Rio de Janeiro.

Integraram o grupo de entrevistados cinco universitários indígenas, sendo quatro homens e uma mulher. O grupo estava constituído por adultos com idades entre 24 e 42 anos, quatro dos cinco entrevistados vivem no subúrbio do Rio de 


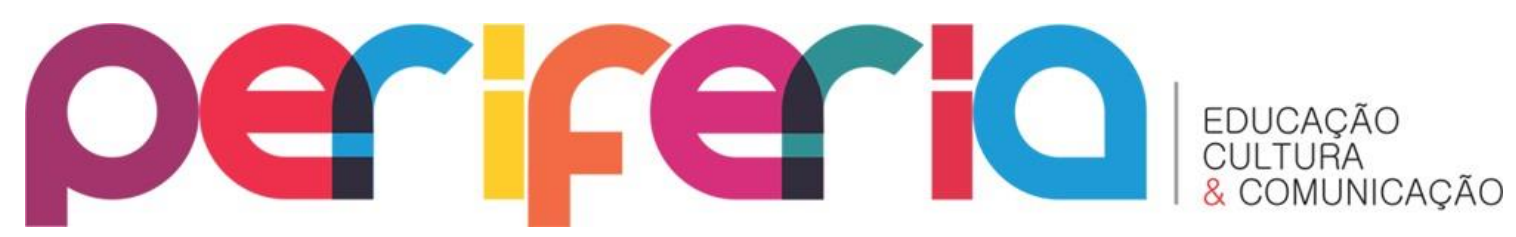

Janeiro e um deles na cidade de Belford Roxo (Baixada Fluminense, Grande Rio). Em relação as suas etnias e tempo de moradia no Rio de Janeiro tivemos, nesse grupo, um homem de etnia Guarany Mbyá (Espírito Santo), que vive no Rio há apenas três anos e que cursa ciências Sociais na UFRRJ - único cotista em universidade pública; os demais matriculados em universidades particulares, sendo um homem da etnia Xavante (Mato Grosso) que está há quatro anos no Rio frequentando o curso de Letras; um homem da etnia Wapichana (Roraima), morador do Rio há seis anos, que estuda Administração; e um homem e uma mulher Tupinambás (Bahia), o primeiro vivendo no Rio há mais de 20 anos e cursando a faculdade de História, a segunda já nascida nessa cidade e estudante de Comunicação Social.

\section{POLÍTICAS DE AÇÃO AFIRMATIVA E COTAS: ALGUMAS OPINIÕES}

De acordo com Moehlecke (2002, p. 198), o termo "ação afirmativa" chega ao Brasil carregado de uma diversidade de sentidos, o que, em grande parte, reflete os debates e experiências históricas dos países em que foi desenvolvido. Em um país estruturado a partir da desigualdade étnica e racial, as ações afirmativas são reduzidas apenas à proposta de cotas e, muitas vezes, questionadas pelo fato de ameaçarem o discurso do mérito.

Se as ações afirmativas têm a função de evitar que a discriminação ocorra por meio de normas de aplicação geral ou específica e, principalmente, por mecanismos difusos, estruturais, enraizados nas práticas culturais e no imaginário coletivo, como aponta Valentim (2012: 72), elas podem, assim, induzir transformações culturais, pedagógicas e psicológicas, quando incidem sobre ideias de supremacia e subordinação raciais, sexuais e outras. Em nenhum momento os entrevistados relacionaram essa possibilidade como consequência do sistema de cotas. Os que conheciam o sistema demonstraram um pouco de incômodo sobre sua necessidade, como se isso ferisse o mérito dos indígenas que chegaram à vida universitária, como demonstra essa fala de outra entrevistada:

[...] pra gente enquanto indígena é muito importante mas não é a 


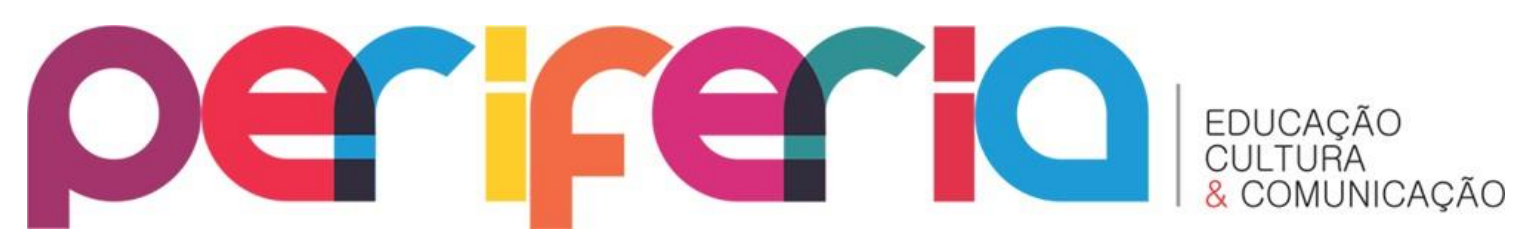

solução, porque eu conheço muitos parentes, que passaram dificuldades, ainda passam dificuldades e não entraram por esse sistema porque quiseram mostrar, que, assim: "eu tô passando dificuldade mas eu sou capaz". O governo ele quer mudar, como eu posso dizer, um espaço, com as cotas, quando ele deveria estar dentro da minha comunidade fazendo algo que... Já me preparando, né, pra eu conseguir passar como qualquer outra pessoa em todos os espaços. (R. Tupinambá)

Outro estudante também critica a deficiência do ensino fundamental e médio oferecido aos povos indígenas e fala do paradoxo existente no ensino superior, onde as vagas nas universidades públicas são preenchidas em sua grande maioria por pessoas que poderiam arcar com as mensalidades em uma universidade particular:

Como eu falei, é culpa do governo não ter me dado possibilidade de ter estudado, de estudar... Você vê que as universidades públicas, é... acho que mais de a metade que estuda nas universidades públicas, não têm essa necessidade, não é pobre, não teve dificuldade. Você vê que os caras têm carro, estudou em colégio particular e tal, então, o que o governo devia fazer que talvez entraria contra a legislação, era não proibir, mas ter critérios com esses caras que podem pagar sua educação, pô, estuda na PUC, estuda em outra universidade, deixa essas vagas pros caras que realmente não tem. (C. Wapichana)

Outras falas apontaram as questões específicas inerentes aos povos indígenas, questionando como esse sistema de cotas poderia ter uma conexão mais direta com as necessidades coletivas das comunidades/povos envolvidos, e não somente os interesses individuais dos estudantes. De acordo com Souza Lima e Hoffmann (2004), as políticas de ação afirmativa precisam adequar-se mais amplamente às especificidades da situação indígena, criando mecanismos de acesso à universidade que levem em consideração a necessidade de instituir políticas voltadas para povos, isto é, "capazes de beneficiar, mais do que indivíduos (ainda que por meio deles), coletividades que pretendem manter-se culturalmente diferenciadas" (idem, 2004, p.16).

Nesse sentido, faz todo sentido a crítica de um dos entrevistados que questiona o critério utilizado por maior parte das universidades que utilizam o sistema de cotas: 


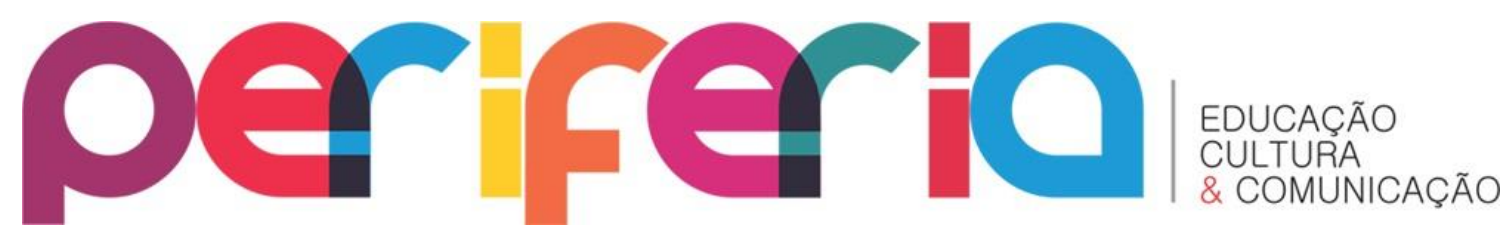

a auto identificação não pode ser o único critério para o reconhecimento étnico, visto que esses estudantes fazem parte e precisam representar seus coletivos. Como alerta esse entrevistado:

Eu não tenho nada contra as cotas, acho que é legal, né, se for o índio mesmo pra ocupar as vagas... As cotas acho bacana, né, [o problema é que] muitas pessoas se passam por índio pra ocupar uma vaga que era do índio, né. (Ab. Guarany Mbyá)

Outro estudante fala da questão da competitividade entre os próprios discriminados, e ressalta a questão da invisibilidade dos estudantes indígenas dentro das universidades brasileiras:

É, ela ainda tem um outro ponto, né, porque as cotas indígenas a gente divide elas com os negros, a cota racial. Então, [...] é extremamente competitivo. Como eu disse anteriormente, povos indígenas no Brasil, eles são invisíveis e quando tem que disputar, tem que disputar [riso] com os próprios discriminados, também, então, é uma questão que eu sempre boto em dúvida sobre essa validade. O que é igualdade racial, o que é igualdade de cotas, na verdade não existe. (Ak. Tupinambá)

As falas desses estudantes, assim como os poucos trabalhos que discutem essa questão, demonstram que, no caso dos indígenas, políticas de ação afirmativa para o ingresso no Ensino Superior não são suficientes sem mudanças muito mais amplas nas estruturas universitárias, de modo que estas reflitam sobre suas práticas a partir da diferença étnica, de um olhar sobre quem se desloca de um mundo sociocultural e, em geral, linguístico, totalmente distinto, ainda que os estudantes indígenas pareçam e sejam - uns mais, outros menos - conhecedores de muito da vida brasileira.

Como alertam Souza Lima e Hoffmann:

As cotas têm sido importantes, tanto quanto a demanda do movimento indígenas por espaços de formação. Mas não basta, no caso indígena, criar cotas e esperar que os estudantes indígenas façam por si só todo o trabalho que um sistema de ensino inteiro precisaria fazer, ou jogá-los em escolas de péssima qualidade fabricantes de títulos, nem escolher 3 ou 4 indígenas para serem objeto de um assistencialismo rançoso. 


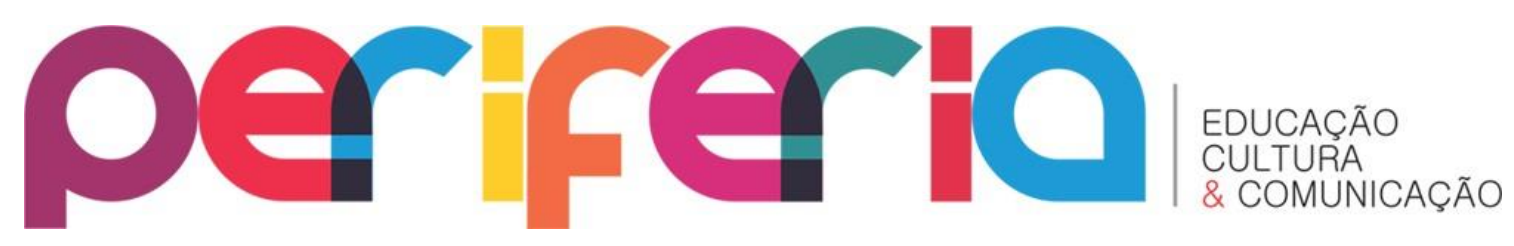

(LIMA e HOFFMANN, 2004, p. 21).

A falta da participação de representantes indígenas durante a discussão sobre a elaboração e o desenvolvimento de políticas de ação afirmativa foi outra crítica levantada por esse grupo de estudantes. Sendo assim, durante as entrevistas, também solicitamos que cada estudante universitário indígena apontasse possíveis sugestões de como as políticas de acesso e permanência de indígenas nas universidades poderiam melhorar.

Um dos entrevistados apontou a necessidade de se criar um espaço para estudantes indígenas dentro da universidade, espaços administrados por indígenas e não por terceiros, que ela chama de "interlocutores":

Algo que realmente dê subsídio a essas demandas [dos indígenas], algo que realmente atenda essas demandas, que não seja só, algo, assim, "Ah, aqui tem um espaço dentro da universidade que é só pra indígena. Vocês podem fazer o que vocês quiserem... Vocês podem, é... desenvolver aqui várias coisas que vocês quiserem". E aí você entra nesses espaços mas não são indígenas que estão neles, né. [...] Existe muito isso, principalmente no estado do Rio de Janeiro, [...] você não vê indígenas na frente desses espaços, você sempre vê um interlocutor, [...] Não tem mais necessidade de ter esse interlocutor. Eu acho que é válido todos estarem juntos, até no mesmo espaço, assim, que a troca de saberes, de conhecimento vai construir junto, mas eu também vejo como é importante termos espaços próprios, para o nosso fortalecimento dentro das cidades e das universidades e não entendo essa necessidade, em alguns desses espaços, de ainda possuir esses interlocutores não indígenas, que tomam à frente em nosso nome. (R. Tupinambá)

Outro estudante confirma a necessidade da existência de espaços próprios para os indígenas e aponta algumas estratégias para que esse estudante também se sinta reconhecido no ambiente acadêmico, fator importante para diminuir os índices de evasão:

Permanecer na universidade é uma coisa complexa. Primeiro que tem os mecanismos de saudade, distância, trabalho, vivências, nova sociedade, é... A universidade tem várias sociedades internas, seus valores culturais, é... A gente tem 


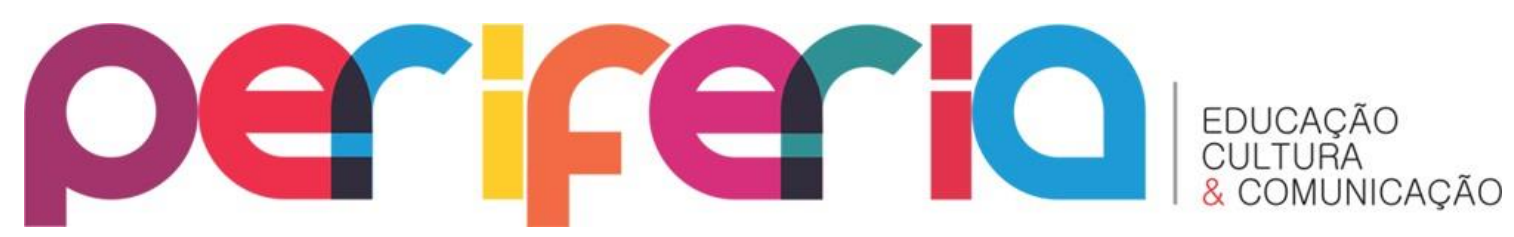

pensado muito na produção de uma república à qual dias de sábado, dentro da universidade, ele tenha que vir a dar aula cultura, da cultura dele para outros indígenas e não indígenas. $\mathrm{O}$ que fortalece ele, culturalmente, dentro dessa sociedade, e valorar ele, ele vai se valorar e valorar a cultura do outro, aprender sobre a cultura do outro. Então, esse é um dos mecanismos. (Ak. Tupinambá)

A necessidade de que políticas que visem a inclusão de indígenas no ensino superior também considerem o debate sobre o respeito e o reconhecimento da diversidade cultural e da valorização dos conhecimentos indígenas dentro do sistema acadêmico apareceu também em outro depoimento:

[...] quando se fala de melhorar é principalmente ter respeito, né, ter respeito pelos grupos indígenas, respeito pelos conhecimentos tradicionais. E assim, abordar o conhecimento assim do índio, dentro da universidade, nas matérias, assim, dialogando esses saberes que também são científicos, mas não são reconhecidos nessa academia. (Ab. Guarany Mbyá)

Além da questão do reconhecimento e de espaços e estratégias que possibilitem o fortalecimento étnico no interior das universidades, também foi apontada a ausência de mecanismos que permitam ao estudante condições de alimentação, transporte, moradia e disponibilidade de material de estudo de forma diferenciada. Grande parte desses estudantes são provenientes de outros estados, e vários deles estão em universidades privadas, e não nas públicas, como alerta esse universitário que não foi incluído na política de cotas:

[...] a universidade não tem preocupação alguma [com a permanência de estudantes indígenas], mas eles também aproveitam isso dentro das estatísticas, nós fazemos isso e tal, mas não é... Você sabe que pro ser humano se manter na faculdade precisa de transporte, alimentação, segurança, tem que ter material, tem que ter alimentação, todo um conjunto de coisas... (C. Wapichana)

Esses relatos e depoimentos comprovam como muitos indígenas conseguiram, e ainda conseguem, por esforço pessoal - e hoje por política assumida por muitas organizações indígenas, que financiam ou apoiam estudantes indígenas para que 


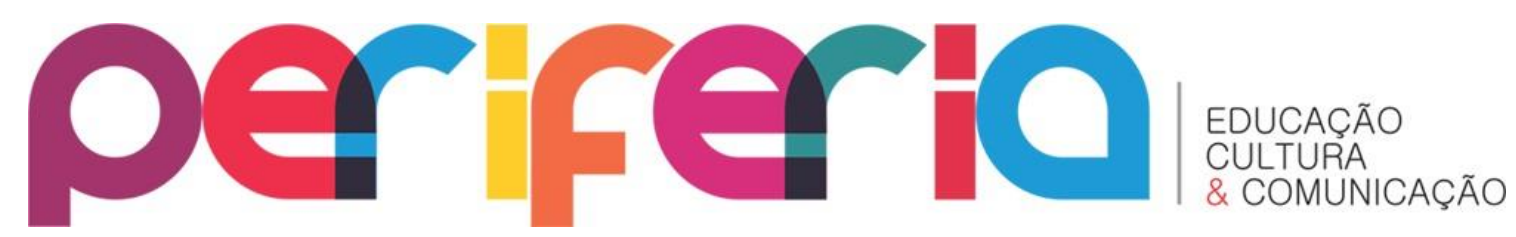

estudem nas cidades e adquiram conhecimentos que revertam a suas comunidades entrar em universidades, mas manter-se nelas tem sido o maior desafio.

Como Souza Lima e Hoffmann (2004) apontam, os intelectuais indígenas possuem bastante clareza de que, se o acesso às universidades é importantíssimo, as cotas podem servir como um instrumento valioso para a situação de povos territorializados - ainda que muitos de seus integrantes estejam em trânsito permanente entre esses territórios e ambientes urbanos próximos ou distantes deles, ou que nesses territórios suas aldeias muitas vezes estejam adquirindo o perfil de cidades. Além destes, as cotas também servem de instrumento para estudantes que, muitas vezes motivados pela busca da educação, se deslocaram para os centros regionais ou mesmo para cidades distantes, como Brasília, São Paulo e Rio de Janeiro.

Os estudantes indígenas que fizeram parte dessa pesquisa confirmam a importância que o acesso ao Ensino Superior possui para suas trajetórias individuais, mas, sobretudo, para as melhorias possíveis dentro de suas comunidades de origem. Todos os estudantes disseram que, entre as razões de ingresso ao ES, está o desejo de apoiar as causas e buscar soluções para questões fundamentais para o desenvolvimento de suas comunidades. Também disseram ter como meta o retorno às suas aldeias e territórios, como profissionais que irão ocupar cargos de liderança ou de apoio para conquistar e defender os direitos de suas populações.

\section{VIDA ESCOLAR: TRAJETÓRIAS DE SUPERAÇÃO}

Ao serem questionados sobre suas trajetórias escolares, todos os estudantes disseram ter tido um cotidiano de muita dificuldade já nas instituições de educação básica. Para aqueles que cursaram em escolas das aldeias, uma das dificuldades era a falta de professores qualificados ou a necessidade de se conviver com a violência e o preconceito:

[...] eu estudei até uns 7 anos de idade dentro da aldeia, lá em Mato Grosso do Sul [...] e fui alfabetizado em língua portuguesa, mas naquela época era muito difícil assim, ter um professor bilíngue dentro da aldeia, era mais FUNAl e eu 


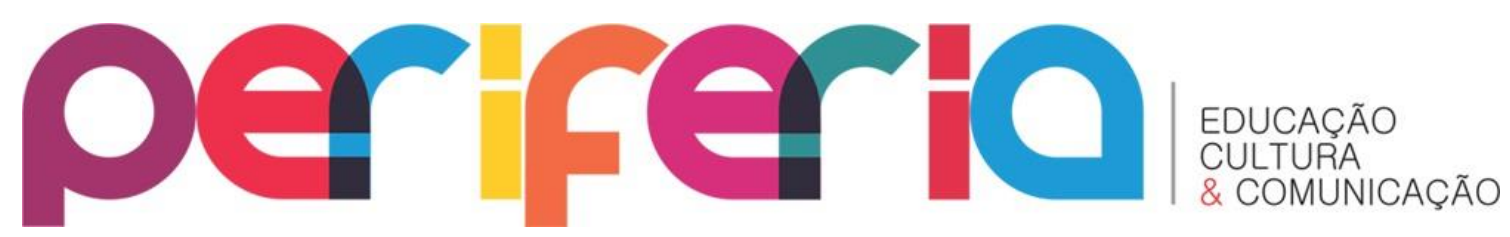

estudei até $4^{\mathrm{a}}$ série, na 5 a série tive que fazer numa escola rural, que não era mais dentro da aldeia. Então, fica difícil quando você lembra das coisas do passado... Até hoje, às vezes, você não quer lembrar das coisas que você viveu, que você sofreu durante a sua trajetória de vida. Por exemplo, na zona urbana, eu era o único índio, tinha que estudar no meio dos filhos dos fazendeiros... Então teve essa relação "que eu sou o melhor do que você" e isso até hoje existe. (Ab, Guarany Mbyá).

A única mulher do grupo entrevistado é também a única jovem que nasceu na cidade do Rio de Janeiro. Importante destacar que sua educação sobre a realidade de sua etnia se dá no âmbito familiar, através de sua avó materna. A entrevistada ressignifica isso, aproximando esta sua experiência particular com aquela vivenciada nas aldeias, procurando fortalecer sua identidade indígena apesar de viver na "cidade grande":

[...] a gente que vive pelo contexto urbano a gente passa por um outro processo, né? [...] A educação indígena é através do exemplo, a gente não aprende através dos livros, não é como a outra educação, né? É através do exemplo, a gente tem a cultura no dia a dia e na cidade é bem difícil, assim, mas sempre é um mais velho que passa, né? É um avô, uma vó, uma pessoa próxima, e de mais idade na família, que desde que você nasce tá ali, assim, do seu lado, meio que dando um subsídio, te dando um pouco do saber, né, e... Mostrando da cultura. E quando eu fui a comunidade, foi algo que eu fiquei muito impressionada, porque eu cresci na cidade mas, tudo que eles sabiam era o que eu tinha aprendido com a minha vó. (R. Tupinambá).

Sobre as dificuldades vivenciadas durante suas trajetórias na educação básica, procuramos apontar, através dos depoimentos, quais teriam sido suas maiores dificuldades e desafios enfrentados ainda neste percurso prévio ao cotidiano universitário:

Nós, povos guarani, somos povo da oralidade, né, não somos de escrita não, então quando você entra numa escola, onde a escola está ensinando uma língua que não é seu, uma língua que foi trazido para dentro da escola indígena, parece que você tá, tá saindo do seu mundo e entrando num outro mundo, então quando eu me refiro a outro mundo, é o mundo 


\section{periferio}

da escrita, né, porque se você não é ensinado dentro da sua própria língua, é muito difícil aprender de uma hora pra outra, você tem que passar a viver de novo aquela outra língua do português, por exemplo, né. Então, quando você estuda a sua própria língua, você tem mais facilidade para aprender, de você organizar o que você quer no seu estudo, tudo, mas quando é o contrário... Parece que você tem que nascer de novo para conhecer aquela língua, então, parece que a língua portuguesa interrompe um pouco o que você tá vivendo... Então, acho que as dificuldades é isso, dificuldades e desafios são a língua portuguesa que entra para a escola indígena, né, isso que acaba assim, forçando um pouco. (Ab. Guarany Mbyá).

Destacamos no depoimento acima a dificuldade do estudante indígena que não tem a língua portuguesa como língua materna, mas precisa lidar com essa realidade durante toda a sua trajetória acadêmica, tanto no ensino básico quanto no ensino superior. Existem cerca de 180 línguas indígenas diferentes no Brasil, segundo dados da FUNAI. Apesar dessa diversidade, todo e qualquer material didático incluído no programa nacional de livros didáticos é feito em português, e os editais lançados para atender as demandas indígenas só são pensados para as escolas existentes dentro das aldeias. Sendo assim, os estudantes que precisam estudar fora de suas aldeias, nas escolas das cidades, não podem contar com qualquer suporte ou apoio, não estando incluídos nos projetos desenvolvidos pelo governo federal.

Além da língua, outra dificuldade enfrentada por esses estudantes é o próprio fato de viver nas cidades. Interessante destacar como a entrevistada, neste depoimento, compara a sua situação com a de uma planta nativa que é transportada e sente dificuldade para sobreviver:

[...] é muito forte, quando você está no meio da cidade e tudo que você olha à sua volta é diferente do que você acredita. $E$, assim, o espaço todo pela questão da educação, é como... É... É como uma espécie [planta] nativa de um local, sendo transportada pra outro local, crescendo em outro local que é estranho... Onde tudo não é... Não é a mata nativa da mesma região, né, tá crescendo em outro local... As vezes, não vinga, né... A gente sabe que as vezes não vinga, né, mas, de certa forma a natureza tem essa coisa de se adaptar, né, como a cultura, é dinâmica, porque a cultura não é inerte, a cultura é 


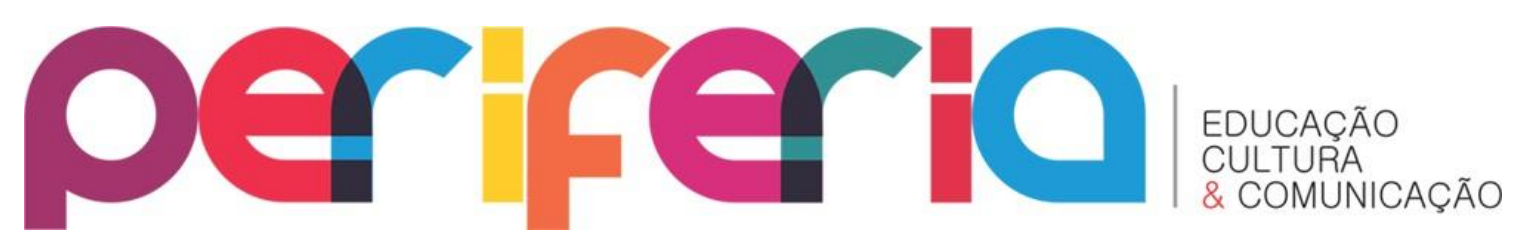

sempre em movimento, e ela é dinâmica. Eu acho que é isso que, de certa forma, faz a gente resistir um pouco, né. ( $R$. Tupinambá).

No caso desta estudante, sua situação é ainda mais ilustrativa, porque não precisou ela mesma ter que viver essa adaptação, mas a geração anterior - seus pais e avós - que veio da aldeia em busca de melhores condições de vida na cidade do Rio de Janeiro. Nesse depoimento, ela também aponta conhecer os debates mais atuais sobre cultura e produção cultural, ao afirmar que "cultura é dinâmica", ou seja, muda, se transforma, mas sem deixar de ser ou sem ameaçar a identidade construída e reafirmada cotidianamente e coletivamente. E, segundo sua visão, será essa constante transformação que fará com que essa cultura própria possa "resistir" em meio a tantas adversidades.

Em relação ao cotidiano na universidade, ou seja, a relação com os demais colegas, com os professores, nota-se, nos depoimentos a seguir, uma convivência bastante superficial com os demais colegas da universidade, apontando o distanciamento cultural entre esses mundos tão diferentes:

Alguns professores, pouquíssimos, a partir do momento que eles me conhecem, é... a gente começa a bater alguns papos, mas outros professores não, outros professores são resistentes...(C.Wapichana)

Além da convivência superficial na universidade, o depoimento a seguir aponta para a necessidade de existir um centro de apoio para atendimento aos estudantes indígenas, preparado para oferecer suporte para esses estudantes que não falam o português como primeira língua e que fazem parte de grupos culturais específicos e diferenciados:

O que eu vejo na universidade é que não dá tempo pra você sentar, tirar dúvida: é correria. Então, eu vejo muita diferença como se fosse cada um... [Muito] individual: vai lá e tal, mas tem pessoa boa lá dentro. Sempre vai querer te ajudar, socorrer... Então eu vejo isso. É.... se prepara mesmo. Tem que buscar não adianta. A maior dificuldade que eu vejo é isso. (S. Xavante). 


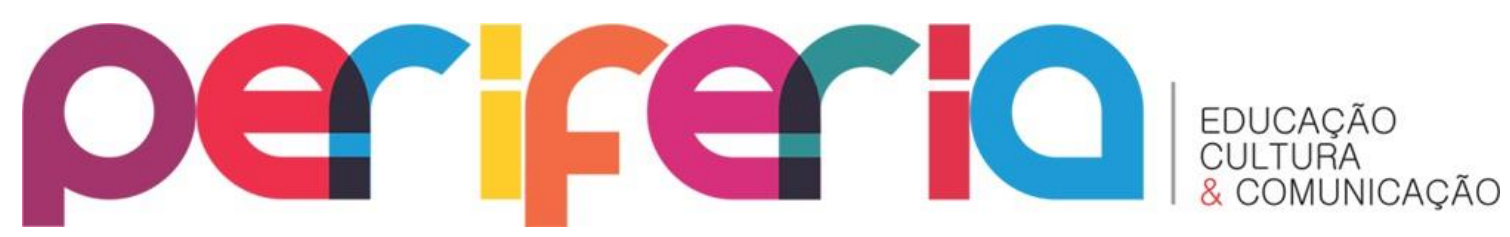

A fala dessa estudante, aponta para o preconceito que os estudantes indígenas precisam lidar no cotidiano da vida universitária, preconceito este que eles vivenciam na relação com os professores, demais estudantes e mesmo na própria organização departamental, o que ela chamou como "estrutura acadêmica":

Eu vou ser sincera, eu não gosto da estrutura acadêmica, porque eu não me encontro na estrutura acadêmica, porque tudo que tá lá, é uma tentativa de... Assim, quando eu falo dentro da... Como posso dizer? Posso estar falando bobagem, mas é muito pessoal também. Mas, dentro da estrutura acadêmica, tudo que está lá é... Como um amigo da etnia Malês, da África, ele fala assim: "Tudo que está na universidade, de certa forma, fica batendo na sua identidade". Tem toda uma estrutura, um outro é... Um outro olhar sobre tudo, né, e que você tem que se adaptar e tem que usar como ferramenta. (R. Tupinambá)

O depoimento a seguir, desta mesma estudante, também aponta como ela reconhece as dificuldades e as limitações do espaço universitário, que não dialoga e também parece querer fragilizar a identidade étnica a qual ela acredita pertencer. Entretanto, ela não deixa de reconhecer que esse espaço e esses conhecimentos são fundamentais para se lutar por direitos:

Você tem que se apoderar dele e usar como ferramenta, saber usar como ferramenta. Se você não sabe usar como ferramenta, às vezes, você se perde dentro daquela estrutura toda e quando você é de outro povo, então, assim, às vezes é muito difícil aceitar algo de que não se acredita. (...) A gente entende que é necessário, a gente vive... Toda a sociedade envolvente a nossa volta, né, torna tudo isso necessário, a gente sabe que é necessário. Então, a gente se apodera enquanto ferramenta, né, se apodera pra poder, como posso dizer, é... representar nosso grupo étnico dentro daquelas profissões, né. (R. Tupinambá).

Durante as entrevistas, foi solicitado aos entrevistados que contassem situações concretas de preconceito que tivessem vivenciado e como eles reagiram nessa situação. Todos os entrevistados afirmaram ter vivenciado situações de 


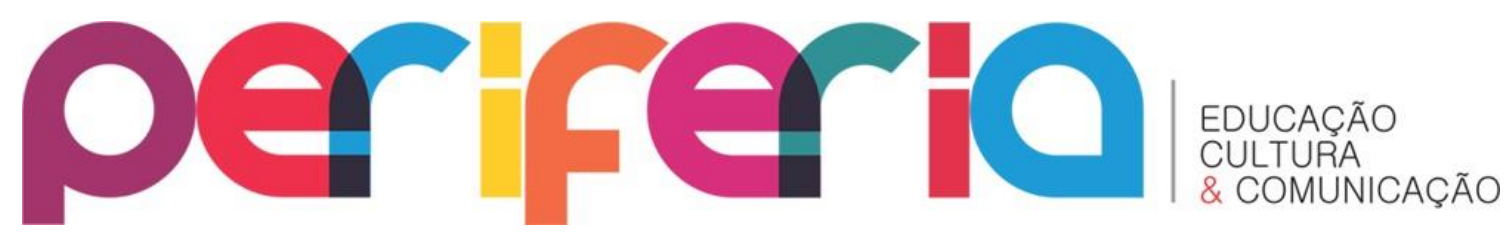

preconceito: algumas vezes de forma velada e indireta, em outras, expressões mais violentas e explícitas de discriminação:

\begin{abstract}
Nas ruas da cidade, na universidade, a gente caminha no cimento e a gente... Elas nos encaram, se a gente tá com roupa da cultura elas nos encaram, se a gente tá pintada elas nos encaram. Ou elas ficam assustadas ou é motivo, assim, de chacota, sempre o diferente... O diferente é muito difícil de ser aceito nessa sociedade, qualquer diferente, não é só nós indígenas, mas todos que são diferentes, né. $\mathrm{E}$, de certa forma, sempre acontece alguma coisa relacionada a isso. Hoje a gente é motivo de fascínio e a gente é motivo de medo ao mesmo tempo. Então, tem isso, tem o fascínio, tem o respeito de alguns, mas também tem o medo de outros, e tem também o preconceito. Tudo ocasionados pela questão da falta de conhecimento. (R Tupinambá).
\end{abstract}

\title{
CONSIDERAÇÕES FINAIS
}

A presença dos estudantes indígenas na universidade pública oportuniza ainda mais a manifestação das contradições, dos paradoxos e das incoerências que nela residem e a constituem, fundamentalmente, a partir das estratégias de ingresso e de permanência desses sujeitos no ambiente universitário.

Há necessidade de estudo, e orientação e um procedimento mais adequado a essa especificidade. É nela que passam a se constituir e a se identificar como estudantes indígenas universitários - categoria emblemática, uma vez que se forja a partir de relações sociais marcadas por interações, intercâmbios, contradições, resistências, resiliências, ocultamentos, negações e afirmações.

Através das entrevistas realizadas com os cinco estudantes universitários indígenas, apontamos urgência na criação de programas institucionais de inclusão e acompanhamento desses estudantes nas universidades brasileiras. Isso deve ser feito por meio de sistemas e mecanismos que permitam a esses estudantes condições de alimentação, transporte, moradia e disponibilidade de material de estudo, com o objetivo de desenvolver e implementar ações no sentido de zelar não só pela permanência, mas, principalmente, reconhecimento e legitimidade étnica, cultural e linguística próprias dessas populações. Para tanto, é preciso identificar e compreender 


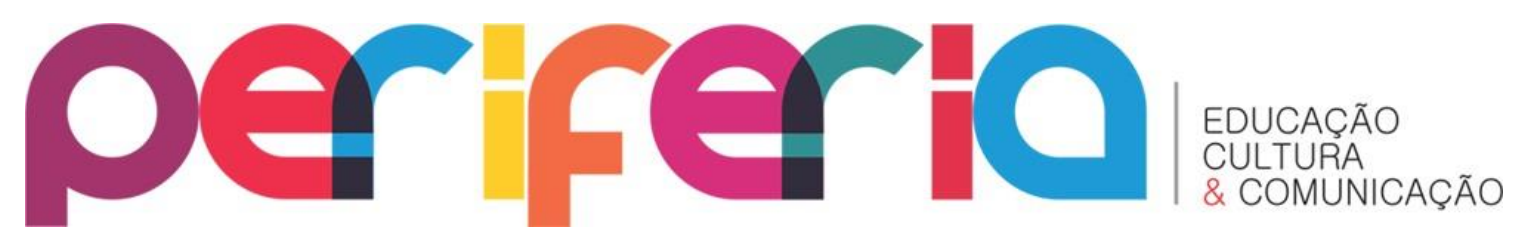

as dificuldades enfrentadas por esses estudantes, e propor medidas que permitam superar as dificuldades. Principalmente, é necessário que as estruturas universitárias sejam repensadas para possibilitarem múltiplas linguagens, espaços, conhecimentos e culturas.

A inserção e adaptação do estudante universitário indígena no contexto urbano no estado do Rio de Janeiro se verificam de forma insatisfatória na universidade e na cidade devido aos seus desafios. A dificuldade de acolhimento pela comunidade universitária é derivada do desconhecimento da diversidade cultural desses estudantes e suas peculiaridades, assim como a ainda incipiente estrutura de recepção.

A universidade assume na narrativa desses estudantes um caráter de espaço de troca, onde, de acordo com seu ideário, eles buscam conhecimentos para potencializar os projetos de vida de sua coletividade indígena. As dificuldades enfrentadas por esses estudantes indicam que a política compele para que o indígena se adapte aos padrões de conceito e assiduidade da sociedade nacional sem levar em consideração a diversidade originária, e sem critérios que analisem sua trajetória como um todo.

\section{REFERÊNCIAS BIBLIOGRÁFICAS}

AMARAL, Wagner Roberto do. As trajetórias dos estudantes indígenas nas universidades estaduais do Paraná: Sujeitos e pertencimentos. (Tese de doutorado) Curitiba: PPGE/UFPR, 2010.

ARAÚJO, Ana Valéria et al. Povos Indígenas e a Lei dos "Brancos": o direito à diferença. Brasília: LACED/Museu Nacional, 2006.

BANIWA, Gersen. Educação escolar indígena: avanços, limites e novas perspectivas. ANPED, Goiânia, 2013.

CAJUEIRO, Rodrigo. Os povos indígenas em instituições de ensino superior públicas federais e estaduais do Brasil: levantamento provisório de ações afirmativas e de licenciaturas interculturais. Trilhas de Conhecimento, 2008.

CUNHA, Manuela Carneiro Da. Índios do Brasil: história, direitos e cidadania. São Paulo: Claro Enigma, 2012.

GUIMARÃES, Gleny et ali. Cotas para estudantes indígenas: inclusão universitária ou exclusão escolar? Educação, Porto Alegre, v.33, n.1, p.65-74, Jan./abr.2010. 


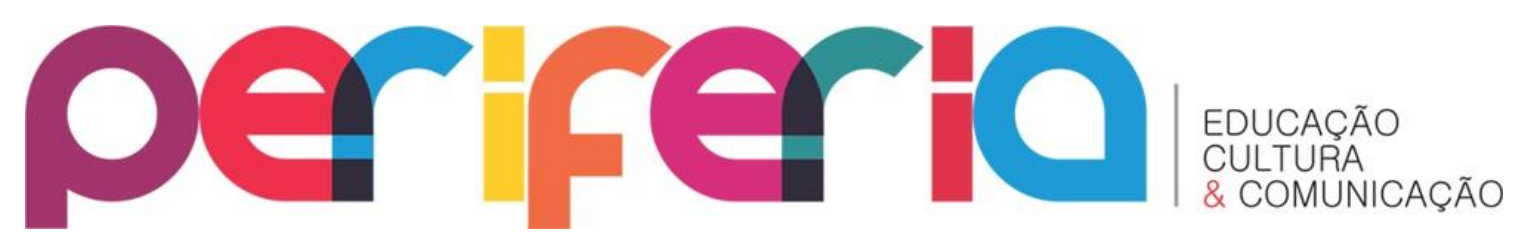

MOEHLECKE, Sabrina. Ação afirmativa: história e debates no Brasil. Cadernos de pesquisa, São Paulo, 2002.

PAULINO, Marcos Moreira. Povos indígenas e ações afirmativas: O Caso do Paraná. (Dissertação de mestrado) Rio de Janeiro: PPE/UFRJ, 2008.

SOUZA LIMA, Antônio Carlos de; HOFFMANN, Maria Barrosso (orgs). Desafios para uma educação superior para os povos indígenas no Brasil. Trilhas de conhecimentos, 2004.

TORRES, Ceres Maria Ramires et al. A contra-reforma da educação superior: uma análise do ANDES-SN das principais iniciativas do Governo de Lula da Silva. Brasília, publicação do Grupo de Trabalho de Política Educacional, 2004. (http://www.andes.org.br acessado em dezembro de 2013).

VALENTIM, Daniela Frida Drelich. Ex-alunos negros cotistas da Uerj: os desacreditados e o sucesso acadêmico. Rio de Janeiro: Quartet: Faperj, 2012. 